\title{
DEVELOPMENT OF A METHOD FOR EXTRACTING MACROPHAGES FROM ZEBRAFISH, DANIO RERIO AND THEIR USE TO ASSESS STRESS
}

\author{
Ahmed MUSTAFA ${ }^{1 *}$, Shree DHAWALE ${ }^{1}$, and Shrikrishna DHAWALE ${ }^{2}$ \\ ${ }^{1}$ Department of Biology, Indiana University Purdue University Fort Wayne, Fort Wayne, IN, USA \\ ${ }^{2}$ Department of Chemistry, Indiana University East, Richmond, IN 47347, USA
}

Mustafa A., Dhawale S., Dhawale S. 2008. Development of a method for extracting macrophages from zebrafish, Danio rerio and their use to assess stress. Acta Ichthyol. Piscat. 38 (1): 73-77.

Background. To assess stress levels in fishes, plasma cortisol levels are measured by radioimmuno assay and phagocytic activity is assessed using macrophages. However, the small size of some fishes makes it difficult to measure stress using these physiological and immunological indicators. In this study, we investigated the possibility of obtaining macrophages from zebrafish via whole body extractions by assessing the respiratory burst activity and phagocytic capacity of extracted cells and we studied the effects of temperature stress on zebrafish using the extracted macrophages.

Materials and Methods. One hundred and fifty genetically pure zebrafish, Danio rerio (Hamilton, 1822), were randomly divided into three groups and placed in three different environments: optimal $\left(28^{\circ} \mathrm{C}\right)$, warm $\left(32^{\circ} \mathrm{C}\right)$, and cool $\left(23^{\circ} \mathrm{C}\right)$. Using the newly developed extraction method described in this article macrophages were extracted from whole fish bodies and the phagocytic activity of these cells were assessed.

Results. The method yielded enough macrophages to examine their respiratory burst activity and phagocytic capacity. Values obtained for experimental replicates were similar and the assessment measures were sensitive enough to detect differences in these parameters among fish maintained at three different temperatures for 2, 4, 6, and 8 weeks. These results suggest that macrophages can be successfully extracted using the whole body method and the extracted macrophages are useful for studying stress.

Conclusion. The method of macrophage extraction described in this article is simple and rapid, and will enable researchers to study the effects of any stressors, environmental or pathogenic, on the non-specific immune response of fish.

Keywords: fish, zebrafish, Danio rerio, stress, macrophage functions

\section{INTRODUCTION}

Macrophages are phagocytic cells that play an important role in both specific and non-specific immune responses. These cells are capable of killing a wide range of pathogens by engulfing them and producing reactive superoxide species (ROS) (Secombes 1996, Babior 2000). These functions are indicators of the non-specific immune response and the general health of the organism, and can be measured by the visible presence of engulfed bacteria and respiratory burst activity. Assays for the measurement of these macrophage functions are widely used for evaluating immune responses in many vertebrates (Pick and Mizel 1981, Ciapetti et al. 1998, Voie et al. 1998) as well as in fish (Secombes 1990, Secombes and Fletcher 1992). In such studies macrophage cells in fish are obtained and isolated from the head kidney (Mustafa et al. 2000,
Brubacher and Bols 2001, Regala et al. 2001, Reynaud et al. 2001), maintained in cell culture, and then checked for the amount of ROS produced during the respiratory burst activity and the number of phagocytized bacteria. Zebrafish, Danio rerio (Hamilton, 1822), are small cyprinid fish that are widely used as genetic models for studying vertebrate development (Haffter and NüssleinVolhard 1996, Dooley and Zon 2000). These fish grow optimally between $25^{\circ} \mathrm{C}$ and $31^{\circ} \mathrm{C}$, and exhibit exceptional fecundity (Sanders et al. 2003). Although, zebrafish are very hardy and tolerant to a wide range of temperatures, there are claims that they do not do well at the upper end of the temperature range mentioned above. They also undergo stress due to frequent handling during production, grading, and distribution, as well as due to other environmental stressors, and they may become vulnerable

\footnotetext{
* Correspondence: Dr Ahmed Mustafa, Department of Biology, Indiana University Purdue University Fort Wayne, Fort Wayne, IN 46805, USA, phone: +001-260-481-6328, fax: +001-260-481-6087, e-mail: mustafaa@ipfw.edu
} 
and particularly susceptible to several maladies such as, Oodinium infection or velvet disease (Westerfield 2000). However, histological and immunological studies on zebrafish are limited. This is probably due to their small size and difficulty in obtaining the minimum amount of plasma to run a radioimmunoassay for stress hormone, cortisol and in extracting sufficient number of phagocytic cells from the kidney.

One solution to this problem is to perform an extraction of phagocytic cells from a whole body and measure their activities. To develop a reliable method that would allow assessment of macrophage function in small fish, we extracted macrophages from zebrafish and investigated the effects of temperature on them. Temperature is one of the stress factors that increases the susceptibility of fish to diseases and is used to study stress physiology and immunology in many fish (Mazeaud and Mazeaud 1981, Wedemeyer et al. 1990, Barton and Iwama 1991). This paper represents a technical update to the researchers for possible use of these procedures to evaluate the effects of stress on immune response that deal with small or larval fish, especially zebrafish. The method of extraction presented here is simple and rapid, and will enable researchers to study the effects of any stressors, environmental or pathogenic, on the non-specific immune response in small fish.

\section{MATERIALS AND METHODS}

One hundred and fifty genetically pure zebrafish, Danio rerio (Hamilton, 1822), were obtained from a fish hatchery (Scientific Hatchery, Huntington Beach, California, USA) and were acclimated at optimum temperature $\left(28^{\circ} \mathrm{C}\right)$ as described by Westerfield (2000). Fish were then randomly divided into three equal groups: one control $\left(28^{\circ} \mathrm{C}\right)$ and two test groups $\left(23^{\circ} \mathrm{C}\right.$ and $\left.33^{\circ} \mathrm{C}\right)$. For each group two replicates (one aquarium per replicate) were used to avoid any tank effects. Fish were maintained in 76-L glass aquaria. Briefly, the aquaria water was filtered and oxygenated using Millennium 2000 filters (Aquarium Systems, Mentor, Ohio, USA) and heated to $28^{\circ} \mathrm{C}$ using Visi-Therm Deluxe $100-\mathrm{W}$ heaters (Aquarium Systems, Mentor, Ohio, USA) and fish were acclimated for 2 weeks. After the acclimation, water temperature in the experimental aquaria was raised to $33^{\circ} \mathrm{C}$ and lowered to $23^{\circ} \mathrm{C}$ over a three day period (one degree on day one and two degrees on days two and three). Througout the study, fish were fed TetraMin: Large Tropical Flakes (The Rich Mix) (Tetra, Melle, Germany) twice a day to satiation and cared for according to the approved protocol (Purdue University Animal Care Usage Committee Approved protocol No. 03-030-06)

Fish samples ( 3 per tank; 6 per group) were withdrawn at 2 weeks intervals $(0,2,4,6$, and 8$)$ and euthanized using lethal dosage of MS-222. Length and weight measurements for each fish were recorded and following Mustafa et al (2000), each fish was placed in $2 \mathrm{~mL}$ Leibovitz-15 (L-15) cell culture medium (Mediatech Inc., Herndon, Virginia USA) containing 2\% fetal calf serum
(FCS) (Sigma Diagnostics, St. Louis, Missouri USA) (said solution also included 100 i.u. penicillin-streptomycin $\cdot \mathrm{mL}^{-1}$ and 10 units heparin $\cdot \mathrm{mL}^{-1}$ ) (Sigma Diagnostics). The entire fish except the head, tail, and fins (referred herein as whole body or whole fish) was then macerated through a fine meshed wired net (E-C Apparatus Corporation, Holbrook, New York, USA). The cells were collected by centrifugation at $170 \times g$ for $15 \mathrm{~min}$ and re-suspended in $1 \mathrm{~mL}$ L-15 with $2 \%$ FCS. Macrophage cells were then checked for viability and counted using trypan blue (Sigma Diagnostics) ( $0.5 \mathrm{~mL}$ of $0.4 \%$ trypan blue $+0.3 \mathrm{~mL}$ of L- 15 $+0.2 \mathrm{~mL}$ of cell suspension to obtain a dilution factor of 5) exclusion test using a hemocytometer. The cells were again centrifuged at $170 \times g$ for $15 \mathrm{~min}$ and re-suspended in $1 \mathrm{~mL}$ L-15 with $0.1 \%$ FCS.

The protocol described by Brown et al. (1996), Mathews et al. (1999), and Mustafa et al. (2000) was used to assess macrophage functions. For respiratory burst activity, $100 \mu \mathrm{L}$ aliquots of each sample were placed, in duplicate, onto glass slides with double etched rings (Erie Scientific Co., Portsmouth, New Hampshire, USA) for macrophages to adhere. Glass slides were then incubated at room temperature for $120 \mathrm{~min}$ for allowing cells to adhere. After incubation, slides were rinsed gently with phosphate buffered saline (PBS) (Sigma Diagnostics) and incubated again for $30 \mathrm{~min}$ at room temperature with nitro-blue tetrazolium (NBT) ) and phorbol myristate acetate (PMA) (both from Sigma Diagnostics). NBT was dissolved in $\mathrm{L}-15$ at $1 \mathrm{mg} \cdot \mathrm{L}^{-1}$ and PMA was added to it at $1 \mu \mathrm{g} \cdot \mathrm{mL}^{-1}$. During $30 \mathrm{~min}$ incubation process, NBT was reduced into insoluble blue formazan giving a color to the active cells. Once the second incubation was complete, the slides were examined under the microscope to determine the proportion of active cells.

For examining phagocytic capacity of macrophage cells, $100 \mu \mathrm{L}$ formalin-killed Bacillus megaterium suspension was added to slides containing macrophage cells that had been extracted and placed onto slides, and incubated for $120 \mathrm{~min}$ as described above. Slides of macrophage cells with added bacteria were again incubated for $90 \mathrm{~min}$ at room temperature, washed with PBS, air dried, fixed in methanol, and stained with Diff-Quick Leukostate Stain (Fisher Diagnostic, Middletown, Virginia, USA) using glass slide staining jars. Lastly, slides were examined microscopically to determine the proportion of macrophage cells capable of phagocytosis (cells containing more than 5 bacteria were considered capable).

The means and standard errors of the means were calculated and analyzed for statistical differences using analyses of variance (ANOVA) and Tukey's test for postANOVA comparison of multiple means. No significant differences were found between the replicates and therefore, the data was pooled for analyses. Differences were considered significant when $P<0.05$.

\section{RESULTS}

To study the effect of temperature on condition factor of fish maintained at three different temperatures length 
and weight were measured. Data shown in Fig. 1 and Fig. 2 demonstrate that there were no significant differences between the groups (all having $P>0.05$ ). Therefore, condition factors data are not presented here.

Microscopic examination of stained slides revealed that the macrophage preparation were relatively free of other cell types because the majority of the cells show macrophage morphology (Fig. 3). Data for macrophage respiratory burst activities is presented in Fig. 4 and for macrophage phagocytic capacities is in Fig. 5. The values of replicates for each sample for both respiratory burst activity and phagocytic capacity were close to each other suggesting that the method was reliable. Macrophage respiratory burst activity and phagocytic capacity significantly decreased following warm water exposure and remained significantly low throughout the experiment $(P<0.05)$ (Figs. 4, 5). Fish exposed to cooler water also had lower values compared to the control, but did not show any significant difference up to week 6 . However week 6 and week 8 means displayed significant reduction in respiratory burst activity. Also, week 8 means showed significant decrease in phagocytic capacity.

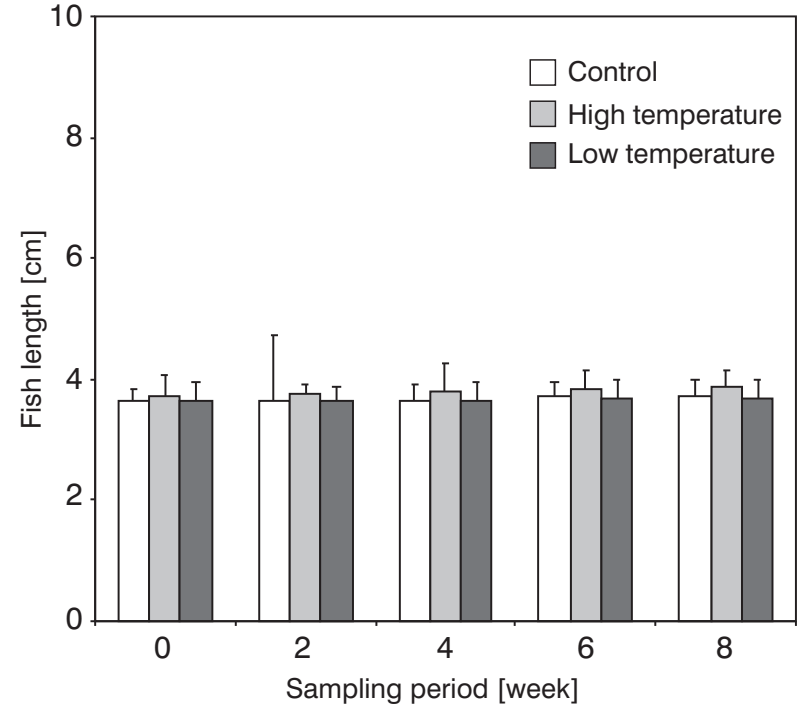

Fig. 1. Total length of zebrafish, Danio rerio, at different sampling periods (mean \pm SEM)

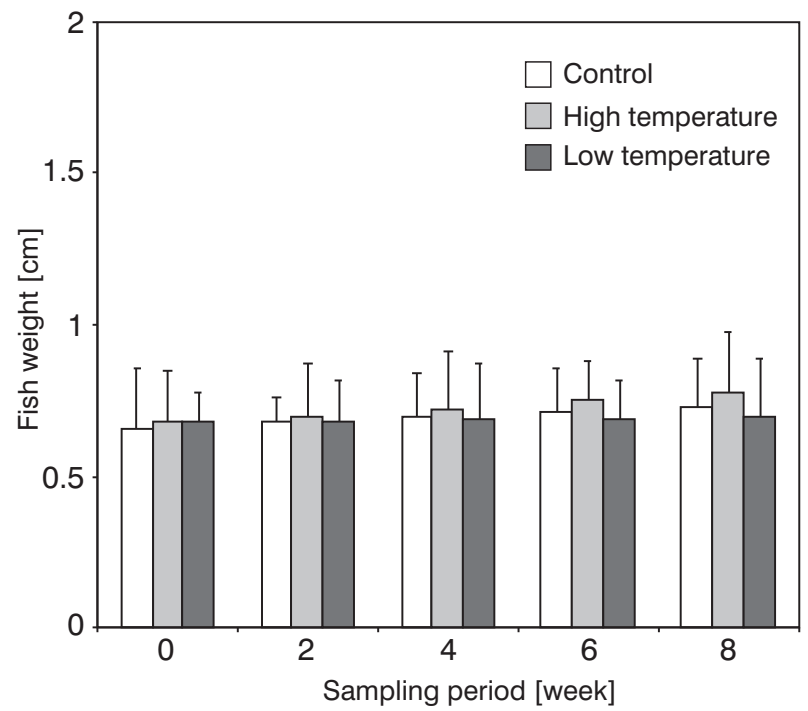

Fig. 2. Weight (mean \pm SEM) of zebrafish, Danio rerio, for control and two experimental groups at different sampling periods

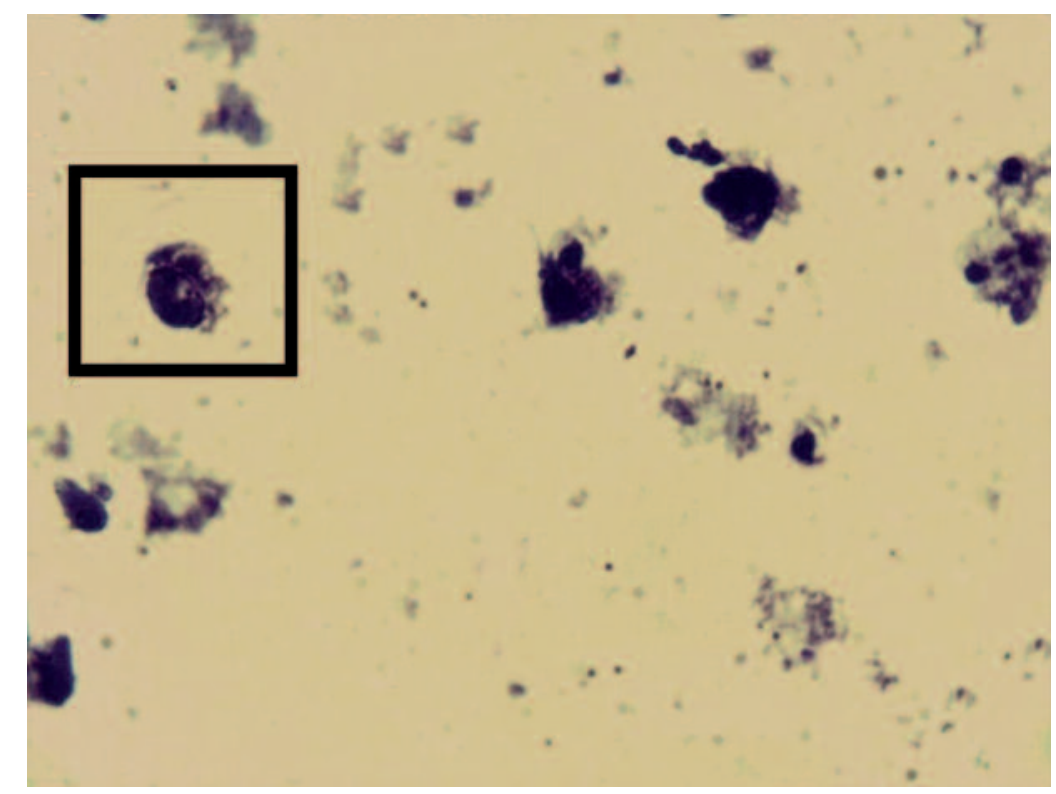

Fig. 3. Light micrograph, showing distribution of macrophages of zebrafish, Danio rerio, on a prepared slide $(\times 100)$; Inset: a macrophage containing phagocytized bacteria $(\times 100)$ 


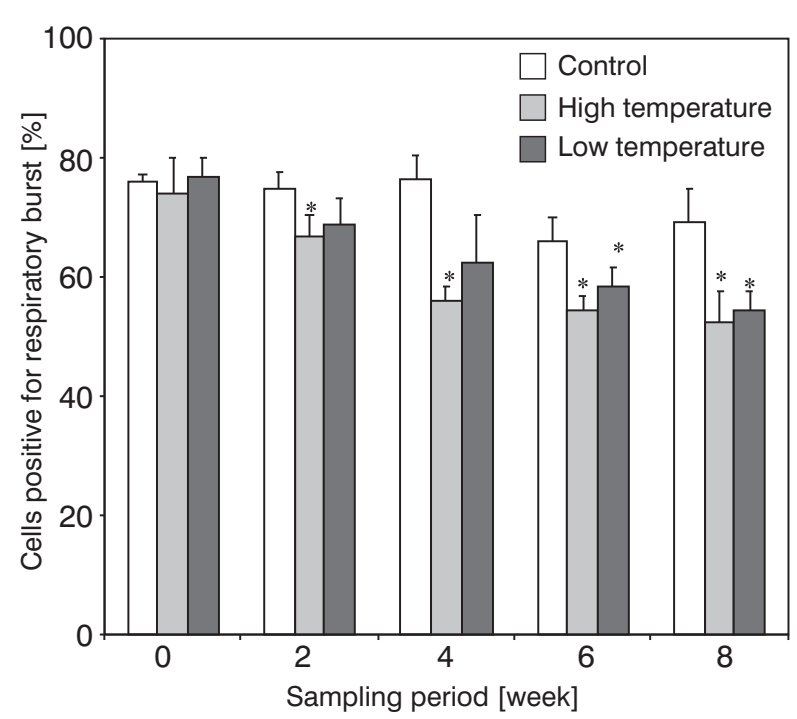

Fig. 4. Percentage of active macrophage cells for respiratory burst activity isolated from control and experimental groups of zebrafish, Danio rerio, (mean \pm SEM); * denotes significantly different from control

\section{DISCUSSION}

The small size of some fish, such as the zebrafish, Danio rerio, makes the isolation of macrophages difficult to use standard methods. In turn, this limits studies of various stressors that rely on assessment of macrophage activity. This paper describes a method of using a whole body extraction of macrophages from zebrafish, and illustrates that macrophages can be obtained in sufficient quantities to assess macrophage function during time of stress. Results also indicate that these extracted macrophages exhibit respiratory burst activity and phagocytic capacity as expected for macrophages isolated from the head kidney of fishes (Brown et al. 1996, Mathews et al. 1999, and Mustafa et al. 2000).

Even though fish produce specific immune response, it is small and delayed and therefore, the non-specific immunity is considered as the first line of defense and a considerable part of the immune response unlike mammals (Verlhac and Gabaudan 1994). During phagocytosis, macrophage cells, when stimulated, produce highly reactive oxygen intermediates (ROI) to destroy the pathogens (Bayne and Levy 1991). This function can be affected by many physical, chemical, or environmental factors, known as stressors, and temperature is one of them. According to Barton and Iwama (2000), when the stress is persistent, the organisms lose the tolerance limit and reach the maladaptive stage and suffer from physiological and immunological consequences. Macrophage functions, therefore, decrease significantly in stressed animals. In this study, we see the similar effects as the consequence of heat or cold stress.

To assess the macrophage functions, phagocytic cells are usually derived from spleen, peritoneal cavity or blood of higher vertebrates or from head kidney of larger fish. However, due to the small size of zebrafish it is not

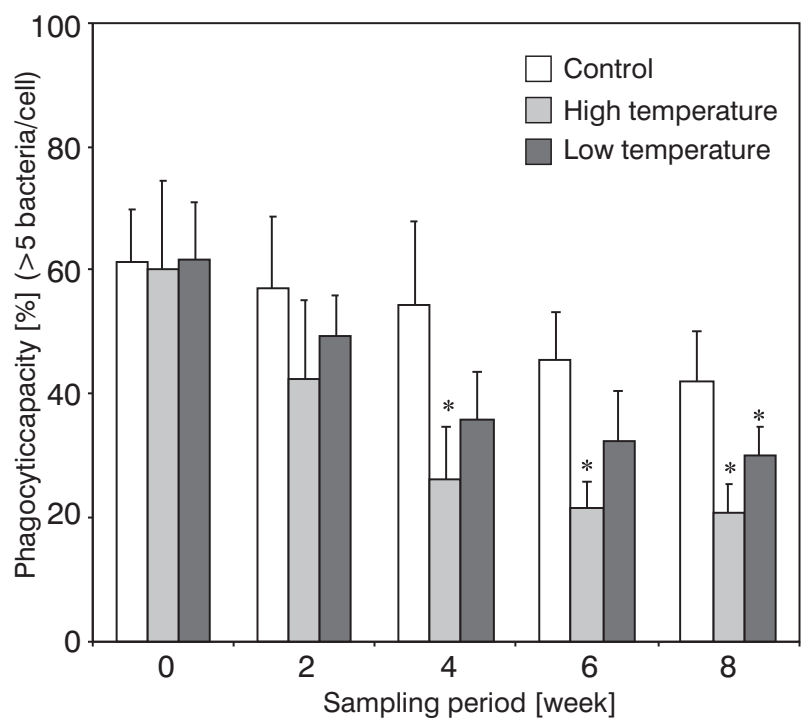

Fig. 5. Percentage of macrophages isolated from control and experimental group of zebrafish, Danio rerio, capable of phagocytizing bacteria (mean \pm SEM); * denotes significantly different from control

very easy to obtain macrophages from these tissues. Hence in our study, we derived macrophages from a whole body (without head, tail, and fins) that includes phagocytic cells from kidney, blood, and peripheral distributions. Using whole body yielded enough cells and facilitated the assessment of macrophage function. The assumption behind this was that macrophages in the periphery would work similarly to macrophage cells from spleen or head kidney to encounter and phagocytize pathogens when exposed. Microscopic examination of samples demonstrated that the vast majority of the cells adherent to slides was macrophages (Figs. 3, 4). We expected this because it is known that fish macrophages can be isolated from other cell types due to their ability adhere to glass slides (Secombes 1990, Crumlish 1998). Although recent trend is to identify macrophages using an antibody for macrophage colony stimulating factor receptor, we could not use that approach because none of the commercially available antibodies have been tested against zebrafish macrophages. Also, the possibility of those antibodies cross reacting with zebrafish macrophages appears minimal because the epiotopes used for producing those antibodies show only $66 \%$ identity (C. Johnston*, personal communication). However, given that our cell preparations appeared to lack significant contamination by other cells and the basic isolation method is identical to that used to isolate head kidney macrophages from other fish (Crumlish 1998, Mustafa et al. 2000) it is clear that the method of macrophage extraction was successful. It is also important to note that in the protocol used in this study only the macrophages were counted.

To demonstrate the usefulness of our method we assessed the effect of temperature on zebrafish phagocytic activity. Our results indicate that temperature is an environmental factor that caused stress to zebrafish and 
reduced the immune response when they were chronically exposed to higher or lower than optimal temperature despite the fact that there were no significant differences in body length and weight. Furthermore, the results also show that our method of extracting macrophages to determine their activities yielded reproducible values and was sensitive enough to detect distinct levels of respiratory burst activity and phagocytic capacity that corresponded to distinct levels of heat stress.

\section{ACKNOWLEDGEMENTS}

We thank Ms. Fatema Majid (graduate student in the Department of Biology at Indiana University Purdue University Fort Wayne) for her help in maintaining fish, collecting samples, and counting cells. We also thank Indiana University Intercampus Research Fund (Research and the University Graduate School) for supporting this research.

\section{REFERENCES}

Babior B.M. 2000. Phagocytes and oxidative stress. American Journal of Medicine 109: 33-44.

Barton B.A., Iwama G.K. 1991. Physiological changes in fish from stress in aquaculture with emphasis on the response and effects of corticosteroids. Annual Review of Fish Diseases 1: 3-26.

Bayne C.J., Levy S. 1991. The respiratory burst of rainbow trout, Oncorhynchus mykiss (Walbaum), phagocytes is modulated by sympathetic neurotransmitters and the 'neuro' peptide ACTH. Journal of Fish Biology 38: 609-619.

Brown L.L., Iwama G.K., Evelyn T.P.T. 1996. The effects of early exposure of Coho salmon (Oncorhynchus kisutch) eggs to the p57 protein of Renibacterium salmoninarum on the development of immunity to the pathogen. Fish and Shellfish Immunology 6: 149-165.

Brubacher J.L., Bols N.C. 2001. Chemically de-acetylated 2', 7' dichlorodihydrofluoroscein diacetate as a probe of respiratory burst activity in mononuclear phagocytes. Journal of Immunology Methods 251: 81-91.

Ciapetti G., Granchi D., Verri E., Savarino L., Cenni E., Savioli F., Pizzoferrato A. 1998. Fluoroscent microplate assay for respiratory burst of PMNs challenged in-vitro with orthopedic metals. Journal of Biomedical Material Research 41: 455-460.

Crumlish M. 1998. Sampling for macrophage cells at the pondside. AAHRI (Aquatic Animal Health Research Institute) Newsletter 7: 1-3.

Dooley K., Zon L.I. 2000. Zebrafish: a model system for the study of human disease. Current Opinion in Genetics and Development 10: 252-256.

Haffter P., Nüsslein-Volhard C. 1996. Large scale genetics in a small vertebrate, the zebrafish. International Journal of Developmental Biology 40: 221-227.

Mathews E.S., Warinner J.E., Weeks B.A. 1999. Assays of immune function in fish macrophage. Pp. 155-163. In: Stolen J.C., Fletcher T.C., Anderson D.P., Robertson B.S., van Muiswinkel W.B. (eds.) Techniques in fish immunology. SOS Publications, Fair Haven, NJ.
Mazeaud M.M., Mazeaud F. 1981. Adrenergic responses to stress in fish. Pp. 49-75. In: Pickering A.D. (ed.) Stress and fish. Academic Press, New York.

Mustafa A., MacWilliams C., Fernandez N., Matchett K., Conboy G., Burka J. 2000. Effects of sea lice (Lepeophtheirus salmonis Kröyer, 1837) infestation on macrophage functions in Atlantic salmon (Salmo salar L.). Fish and Shellfish Immunology 10: 47-59.

Pick E., Mizel D. 1981. Rapid microassays for the measurement of superoxide and hydrogen peroxide production by macrophages in culture using an automatic enzyme immunoassay reader. Journal of Immunology Methods 6: 211-226.

Regala R.P., Rice C.D., Schwedler T.E., Dorociak I.R. 2001. The effects of tributyltin (TBT) and 3,3', 4,4', 5-pentachlorobiphenyl (PCB-126) mixtures on antibody responses and phagocyte oxidative burst activity in channel catfish, Ictalurus puntutus. Bulletin of Environmental Contamination and Toxicology 40: 386-391.

Reynaud S., Duchiron C., Deschaux P. 2001. 3- methylcholanthrene increases phorbol 12-myristate 13-acetateinduced respiratory burst activity and intracellular calcium levels in common carp (Cyprinus carpio L.) macrophages. Toxicology and Applied Pharmacology 175: 1-9.

Sanders G.E., Batts W.N., Winton J.R. 2003. Susceptibility of zebrafish (Danio rerio) to a model pathogen, spring viremia of carp virus. Comparative Medicine 53: 514-521.

Secombes C.J. 1990. Isolation of salmonid macrophages and analysis of their killing activity. Pp. 137-154. In: Stolen J.C., Fletcher T.C., Anderson D.P., Robertson B.S., van Muiswinkel W.B. (eds.) Techniques in fish immunology. SOS Publications, Fair Haven, NJ.

Secombes C.J. 1996. The non-specific immune system: cellular defenses. Pp. 63-105. In: Iwama G., Nakanishi T. (eds.) The fish immune system: organism, pathogen, and environment. Academic Press, San Diego, CA.

Secombes C.J., Fletcher T.C. 1992. The role of phagocytes in the protective mechanisms of fish. Annual Review of Fish diseases 24: 53-71.

Verlhac V., Gabaudan J. 1994. Influence of vitamin C on the immune system of salmonids. Aquaculture and Fisheries Management 25: 21-36.

Voie Ø.A., Wiik P., Fonnum F. 1998. Ortho-substituted polychlorinated biphenyls activate respiratory burst measured as luminol-amplified chemoluminescence in human granulocytes. Toxicology and Applied Pharmacology 150: 369-375.

Wedemeyer G.A., Barton B.A., McLeay D.J. 1990. Stress and acclimation. Pp. 451-489. In: Shreck C.B., Moyle P.B. (eds.) Methods for fish biology. American Fisheries Society, Bethesda, MD.

Westerfield M. 2000. The zebrafish book. A guide for the laboratory use of zebrafish (Danio rerio). 4th edn. University of Oregon, Eugene, ON.

Received: 30 October 2007

Accepted: 9 May 2008

Published electronically: 20 June 2008 